\title{
Implementation Path Of Reverse Emergency Logistics Based On Civil- Military Integration
}

\author{
Wang Shuang ${ }^{1, a}$, Wu Zhong ${ }^{2, b,{ }^{*}}$ and Wu Guoyi ${ }^{1, c}$ \\ ${ }^{1}$ Wuhan Railway Vocational College of Technology, Economic and Administrative College, Wuhan, \\ Hubei, China \\ 2 Wuhan Business University, Physical Education College, Wuhan, Hubei, China \\ a37716195@qq.com, b7849800@qq.com, c1004491030@qq.com \\ ${ }^{*}$ Corresponding author
}

Keywords: Civil-Military Integration, Reverse Logistics, Emergency Logistics, Logistics Cost

\begin{abstract}
Celebrating the 90th anniversary of the founding of the People's Liberation Army, President Xi stressed "To build a strong army, we must carry out integrated military and civilian development and build a national integrated military and civilian strategic system and capability." Therefore, the integration of military and civilian is a new way to solve the problem of reverse emergency logistics. Reverse emergency logistics evolved from military logistics. Thus, the implementation of civil-military integration of reverse emergency logistics is not only the goal of national defense construction and market economy construction, but also the strategic choice of building socialism with Chinese characteristics. By expounding the significance of the implementation of military and civilian integration reverse emergency logistics, the types and processing process of military and civilian integration reverse emergency logistics, this paper analyzes the problems existing in the current reverse emergency logistics and puts forward the implementation path of reverse emergency logistics based on civil-military integration.
\end{abstract}

\section{基于军民融合的逆向应急物流的实施路径 \\ 王爽1, a ，吴钟2,b, ${ }^{1}$ ，吴国毅1,c \\ 1 武汉铁路职业技术学院, 经济与管理学院, 武汉, 湖北, 中国 \\ 2 武汉商学院, 体育学院, 武汉, 湖北, 中国 \\ a37716195@qq.com, b7849800@qq.com, c1004491030@qq.com \\ “通讯作者}

关键词: 军民融合 逆向物流 应急物流 物流成本

摘要: 习主席在庆祝建军 90 周年大会提出: “推进强军事业, 必须深入推进军民融合发展, 构建军民一体化的国家战略体系和能力。”因此, 军民融合是解决逆向应急物流问题的新思路 与新方法。逆向应急物流是由军事物流发展而来, 实施军民融合逆向应急物流符合国防建设 与市场经济建设的目标, 也是建设中国特色社会主义的战略选择。文章通过阐述军民融合逆 向应急物流实施的意义以及军民融合逆向应急物流的类型与处理流程, 分析现阶段逆向应急 物流存在问题并提出了军民融合逆向应急物流的实施路径。

\section{1. 引言}

近年来, 突发性与灾难性事件频频发生。而此类事件一旦发生, 就需要在短时间内提供 
大量的应急物资保障受灾群众的安全以最大限度的减少灾害或事故的影响。应急物流中“应急” 本带有军事色彩, 但与军事物流不同的是应急物流需以社会利益为主导, 最终服务于受灾人 民。习主席在庆祝建军 90 周年大会提出: “推进强军事业, 必须深入推进军民融合发展，构 建军民一体化的国家战略体系和能力。”因此, 军民融合是解决应急物流问题的新思路与新方 法; 另一方面, 应急物流中包括正向应急物流即应急物资的供应与保障以及逆向应急物流即 应急物资使用后的回收与再利用。人们往往关注正向应急物流, 而鲜少研究逆向应急物流。

\section{2. 实施军民融合的逆向应急物流的意义}

\section{1 实施军民融合的逆向应急物流是构建应急物流体系的要求}

在“二战”结束后，根据对军事后勤物流的研究提出了在灾害性或突发性事件中保障资源 供应的应急物流的概念。随着人们不断认识和发展, 出现了世界上第一个应对紧急性事件的 组织一一美联邦应急管理署。可以说, 应急物流是从军事物流发展而来, 并且以政府设立专 门的应急机构为开端。

应急物流是在重大自然灾害以及突发的公共卫生、公共安全以及军事冲突等突发性事件 中对人、财、物等资源的需求而进行的紧急资源保障的特殊物流活动。既然是物流活动, 我 们同样需要研究应急物流体系中的流体、载体、流向、流程与流量等要素, 因此我们对应急 物流体系的认识不应该停留在单向的应急物资的供应保障上，对逆向应急物流问题与管理同 样不容忽视。

\section{2 实施军民融合的逆向应急物流是建设中国特色社会主义的战略选择}

党的十八大以来，着眼于实现中国梦强军梦，将军民融合发展放在推进“四个全面”战略 布局、实践“五大发展理念”的全局中考量, 结合贯彻总体国家安全观、落实新形势下军事战 略方针的要求来运筹, 形成了系统的军民融合发展重要论述。逆向应急物流是由军事物流发 展而来, 实施军民融合逆向应急物流符合国防建设与市场经济建的目标, 也是建设中国特色 社会主义的战略选择。

\section{3 实施军民融合的逆向应急物流是“天灾”、“人祸”频发时代的必然要求}

如今，世界科技虽高度发达，但如地震、泥石流、洪涝灾害、禽流感等突发自然灾害与 公共卫生事件的“天灾”以及如恐袭、地区军事冲突等公共安全的“人祸”随时可能发生。对于 这些突发性事件基本难以预测（有些突发性事件虽有预兆，但与发生时间间隔较短），人、 财、物等资源的时间价值与空间价值难以实现。构建军地结合的逆向应急物流储运中心与成 熟的逆向应急物流网络, 能有效解决对废弃应急物资的处理以及可回收应急物资的再利用。

\section{4 实施军民融合的逆向应急物流对应急物流的经济性提出更高要求}

以 2016 年武汉市洪涝灾害为例，2016 年 6 月底至 7 月中旬的强降雨导致武汉受洪涝灾 害影响严重, 据武汉市民政局统计, 洪涝灾害导致农作物绝收约 74 万亩, 灾害直接经济损 失约 48 亿元。造成巨大经济损失的原因有很多, 但有两个问题值得思考, 第一是此次洪涝 灾害造成工业企业经济损失较大, 武汉市有 8 家直接经济损失过千万的企业, 多是由于积水 过深, 导致厂房、设备、原料及成品被淹。如果能做好灾前的预警和应急逆向物流预案, 转 移和回收部分财产, 那么巨大经济损失有效减少; 第二, 城市雨水回收的应用能有效减轻洪 涝灾害, 通过对雨水的渗储、延排、与再利用等雨水逆向物流管理手段, 建立有效的城市 “生态排水”系统，从而减轻灾害导致的经济损失。

同样的，在应急救灾过程中，将废弃物有效处理、将可回收应急物资回收再利用以及临 时回收调配闲置应急物资等逆向应急物流活动降低应急物流总成本。 


\section{3. 军民融合逆向应急物流的分类与处理流程}

军民融合逆向应急物流是相对于应急物资的流向而言, 所谓正向军民融合应急物流是应 急物资通过军民融合物流系统分发至各个应急点, 而军民融合逆向应急物流指的是由各应急 点通过军民融合物流系统回收使用的应急物资。

根据逆向应急物流的分类处理方式的不同可将逆向应急物流分为:

（1）废弃应急物资物流：是指从应急点回收已丧失使用价值或使用价值不高的应急物 资直至废弃应急物资妥善处理的活动。废弃应急物资虽失去使用价值但可能造成对现有环境 的污染，因此要注意对废弃应急物资的无害化处理，避免环境污染及次生灾害。

（2）可回收应急物资物流：是指从应急点回收可重复使用的应急物资直至该物资二次 利用前的物资流动过程。可回收应急物资可细分为可直接再利用的应急物资如完好的救灾帐 篷、各类救灾机器设备等; 加工再利用应急物资如搭建活动板房的边角余料等。

为了发挥逆向应急物流的价值, 军民融合的逆向应急物流的处理流程为：第一，结合军 队、地方的回收需求进行应急物资收集; 第二, 评估应急物资的使用价值; 第三, 根据应急 物资的价值与再利用性进行分类; 最后, 根据不同类型的应急物资采用不同的处理方法以高 效实施军民融合的逆向应急物流（如图 1 所示)。

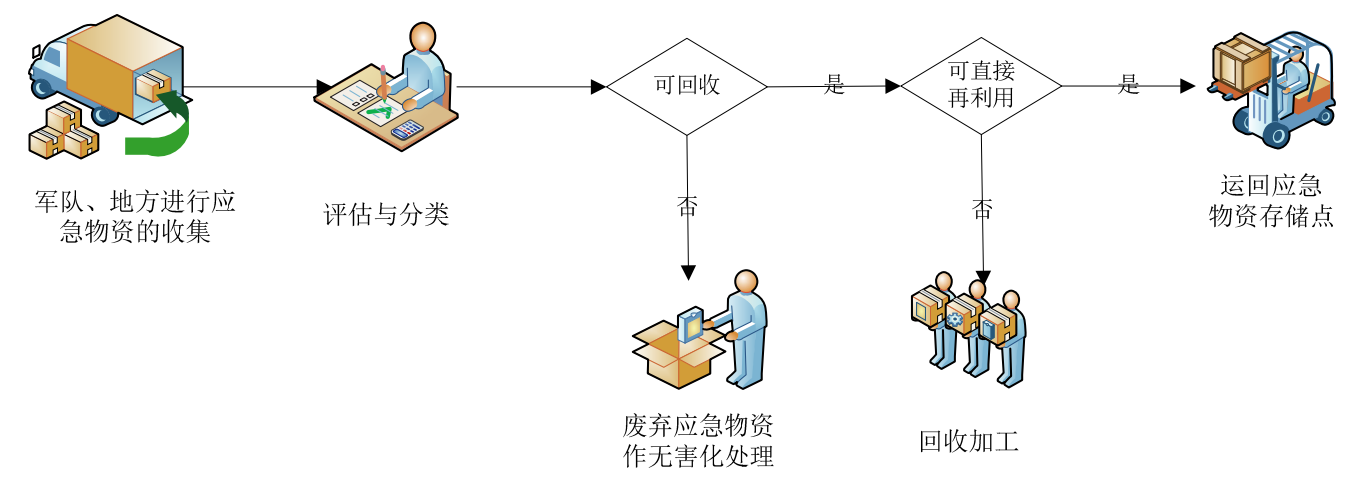

图 1 军民融合逆向应急物流的分类与处理流程

\section{4. 当前逆向应急物流存在的问题}

我国对逆向应急物流也出台了相应的管理办法, 运行过程中也取得了一定的效益, 但对 军民融合逆向应急物流的管理仍存在管理意识缺乏、相关运行机制不健全, 管理模式单一以 及应急物流信息系统建设滞后等较多问题, 制约我国军民融合逆向应急物流的稳步实施与管 理水平的提高。

\section{1 逆向应急物流的意识不强}

逆向应急物流往往发生在应急物资使用之后，在应急物资的运输、调配与使用过程中， 缺乏对应急物资使用情况的详细信息, 对于使用后应急物资的状况, 所处位置以及应急物资 的潜在价值无法评估, 因此对逆向应急物流的价值缺少整体性与重要性的认识; 另外, 往往 在应急救灾过程中, 只重视正向的应急物资的保障与供应而忽视应急物资的回收利用, 缺少 对逆向应急物流工作的统筹。如此导致逆向应急物流的工作难以开展, 运行不顺畅, 大量的 应急物资被闲置甚至浪费。

\section{2 逆向应急物流的有关法律法规与标准建设不完善}

现阶段应急物流关注的是将应急物资提供给受灾地区，应急物资一般是按计划进行分配 与发放的。但是, 受灾地区的应急物资的使用与剩余数量没有统计的标准, 对剩余应急物资 的处理标准相当模糊, 即对军民融合逆向应急物流缺乏清晰, 系统的规划。在制定军民融合 逆向应急物流的相关办法与标准时, 应急物资的分类不详尽, 归口责任不明确, 导致在应急 
物资回收与再分配时没有可依据的标准。虽然民政部出台了《救灾物资回收管理暂行办 法》, 但在执行过程中, 对闲置与剩余应急物资的界定、回流应急物资的分类标准以及回收 成本等问题定义较为模糊, 造成逆向应急物流成本增加, 阻碍了军民融合逆向应急物流的正 常开展。

\section{3 逆向应急物流运作模式单一化}

目前，应急物资的回收采用单一的逆向应急物流运作模式即各级政府管理各自应急物资 的回收与再利用, 这样有利于的废弃应急物资与可回收应急物资的统一处理, 但一般缺少物 资处理专业人员与方法, 因此, 单一逆向应急物流运作效率不高。对于军民融合的逆向应急 物流的运作以及与正向应急物流协调运作的方式尚处于空白状态。

\section{4 逆向应急物流信息处理能力不高}

信息引导逆向应急物流的运转, 是逆向应急物流的催化剂。一方面需要统计应急物资发 放计划, 即对正向应急物流信息及数据准确把握, 但由于应急资源分散, 应急信息缺乏统 筹, 逆向应急物流又是独立运作的, 对应急物流信息系统进行整体开发与综合利用水平较 低。再则, 就逆向应急物流信息系统而言, 其数据资源的管理也是分散的, 信息数据的利用 率较低, 缺少对分散的逆向应急物流数据进行收集、分析、处理、加工与输出等工作, 因此 得到的逆向应急物流数据不完整, 分析与处理的编码标准与接口标准不统一, 无法通过现有 的逆向应急物流信息系统进行集中管控。另一方面, 逆向应急物流信息系统缺少对回流应急 物资进行可视化的追踪, 包括应急物资状态的各类信息如回收时间、地点、回收率、可利用 率等数据, 由于缺少逆向应急物流的信息反馈功能, 导致有关部门不能对逆向应急物资进行 逆向评价, 从而无法修正应急产品的设计, 改良应急产品工艺流程, 提高应急产品质量与应 急物流服务质量。

当然, 当前逆向应急物流存在的问题有着各种主客观原因, 我们有必要实施基于军民融 合的逆向应急物流管理, 有效解决逆向应急物流各种问题。

\section{5. 军民融合逆向应急物流实施路径}

\section{1 贯彻走军民融合实施逆向应急物流的理念}

逆向应急物流一方面能缓解应急资源的缺乏, 另一方面能减少环境的污染。构建逆向应 急物流系统, 需树立军民融合理念, 结合军队、地方的各自的优势, 使逆向物流在应急物流 中产生效益。

（1）军队、地方合作共同完成逆向应急物流的回收作业, 军地双方根据各应急点物资 回收需求生成回收计划, 根据回收计划对各应急点应急物资进行收集、评估、分类与回收处 理。

（2）在逆向应急物流实施中, 应融合军队与地方人才, 各方发挥其职责与特长, 共同 完成逆向应急物流活动。

（3）融合军民逆向应急物流资金, 共同建立应急物资回收专项资金, 按统一标准进行 结算以提高逆向应急物流效率。

（4）融合军民逆向应急物流设施设备, 逆向应急物流设施设备需确保军地通用性, 设 计时应充分考虑军民通用标准。

（5）融合军民逆向应急物流的储配活动, 建立军民联合指挥部, 共同选择配送中心, 统一编组配送车辆, 协调配送路线与配送方式, 共同回收应急物资。 


\section{2 军民融合构建逆向应急物流法律规章与作业标准。}

军民融合逆向应急物流的实施离不开全面的通用的逆向应急物流的法律规章制度以及科 学的系统的逆向应急物流标准。军队、地方可按照民政部出台的《救灾物资回收管理暂行办 法》共同制定具体的回流应急物资在收集、评估、检测、分类、回流配送、维修、报废、再 利用等环节作业标准与规则。由于回流应急物资的品类多, 处理方式差别大, 因此需要全面 细化回收鉴定应急物资的作业标准, 相应的制定科学的回流应急物资分类与处理标准。对已 有的逆向应急物流规章制度需加快补充完善, 在逆向应急物流中未涉及的和新出现的回流应 急物资，应尽快建立相关的分类处理标准，推进军民融合逆向物流标准化制度的建设。

\section{3 建立军民融合的双向应急物流协作模式}

不管应急物流是正向还是逆向的，他们都处于应急物流网络系统中，因此建立军民融合 的双向应急物流协作模式是逆向应急物流活动高效运行的保障。促进军队与地方的高度合作 与相互协调, 增强应急物流系统的灵活性, 使军地逆向物流资源不断整合, 逐渐形成完整的 双向一体化的应急物资供应链系统 (如图 2 所示)。

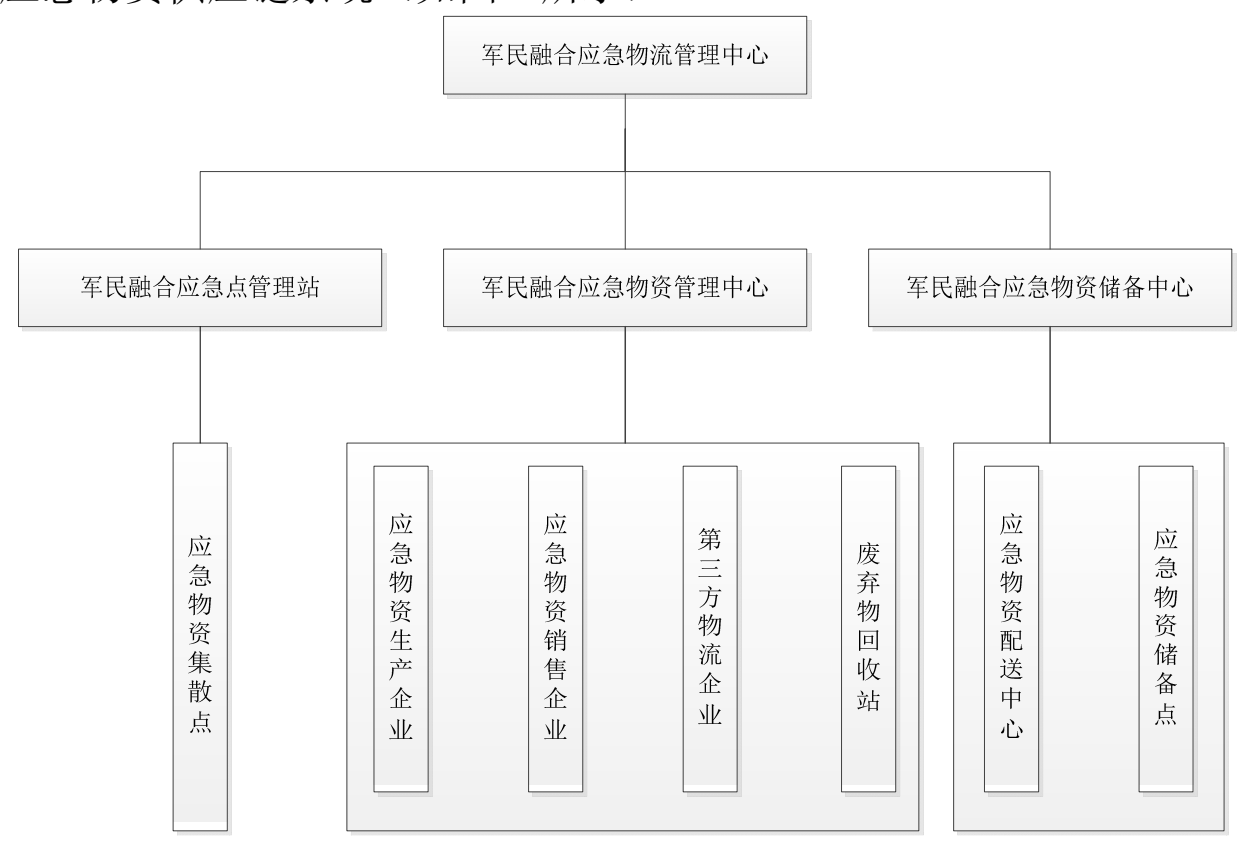

图 2 军民融合双向应急物资供应链系统

\subsection{1 建立军民融合应急物流管理中心}

构建军民融合的双向应急物流系统首先需要建立军民融合应急物流管理中心，通过应急 物流管理中心，规划应急物流网络中应急物资的收集、调度、配送与回收等双向流动，协调 管理应急物资双向流动中的应急点管理站、应急物资管理中心以及应急物资储备中心三个下 设部门的工作，规划应急物资的采购与回收方案，统筹军队、地方逆向应急物流活动，以提 高应急物流系统的运作效率。

\section{3 .2 建立军民融合应急点管理站}

应急点管理站规划应急点的规模、所处位置以及应急点的数量，主要统筹应急物资的集 散与回收，不同应急点的应急物资的调拨与应急信息的管理。在逆向应急物流活动中，应急 点管理站协调军队、地方在各应急点回收可重复使用的应急物资同时对废弃物进行回收与处 理。

5.3.3 建立军民融合应急物资管理中心

应急物资管理中心是协调应急物资的生产与销售企业、军民应急物资储配企业、废弃物 处理单位等一线应急物流组织。他们与应急物资管理中心签订双向应急物流协议。应急物资 
管理中心在平时组织军队与地方的协议企业参与应急演习, 一旦遇到突发性紧急性事件, 应 急物流管理中心根据应急点管理站提供的应急物资需求紧急调度各协议单位的应急资源。随 着应急救援的开展, 各应急点开始出现闲置应急物资。此时, 应急点管理站将可重复利用应 急物资回收信息反馈至应急物资管理中心，再由应急物资管理中心确定回流应急物资去向， 联合应急物资储备中心完成逆向应急物流活动。

\section{3 .4 建立军民融合应急物资储备中心}

应急物资储备中心负责规划一线应急物流企业，保障应急物资供应。根据军队与地方储 配特点选择合适的储备单位与废弃应物资处理单位, 定期检查各一线应急物流企业应急物资 的储备状况。

\subsection{5 建立军民融合的一线应急组织}

军民融合的一线应急组织包括应急物资的生产与销售企业、军民应急物资储配企业、废 弃物处理单位等。通过军民融合的应急物流管理中心的领导与军民融合的应急点管理站、应 急物资管理中心及应急物资储备中心的指导, 军民融合的一线应急组织共同参与完成双向应 急物流协作。

\section{4 提升军民融合逆向应急物流信息化水平}

建立军民融合的双向应急物流信息系统，不断提升逆向物流信息化水平，解决逆向应急 物流信息管理的瓶颈问题，实现逆向应急物流经济、高效、易控及绿色的管理目标。一方面， 军队与地方需引进先进的物流信息技术，通过对逆向应急物资的回收原因与处置情况进行编 码, 统计回流应急物资的回流率与回收再利用率实现逆向应急物流全程实时跟踪与评价。另 一方面，军民融合逆向应急物流信息系统应与正向应急物流信息系统对接，军队应急物流信 息系统与地方应急物流信息系统对接，实现实时信息共享，实现军民融合的正逆向应急物流 信息资源的最佳配置。

\section{References}

[1] Huo Ju, On the implementation path of the five Strategies of military and civilian Integration military reverse Logistics, Defence Industry Conversion in China, vol.05, pp.18-22, 2014.

[2] Lin Zhaoyang, Construction of Reverse Emergency Logistics Management Mechanism, Modern Business, vol.34, pp.125-126, 2016.

[3] Lin Kuixing, Research on the Construction of military and civilian Integrated Emergency Logistics system, Journal of Chifeng University(Natural Science Edition), vol.33, pp.110-112, 2017.

[4] He Qian, Zhu Yongli and Yang Wenhua, The Construction of military and civilian Integration Logistics support system, Journal of Military Transportation University, vol.18, pp.52-55, 2016.

[5] Jiang Yuhong and Liu Xiaobo, Research on the Model of military and civilian Fusion Emergency Logistics Distribution, Logistics Technology, vol.36, pp.164-167, 2017.

[6] Wu Yiwei and Zhao Lindu, Research on inventory Control of Emergency Logistics based on reverse Recycling, Logistics Technology, vol.11, pp.117-119, 2007. 